\title{
Identical Dependence of Dialysate-side Mass Transfer Coefficient on Reynolds Number Using Dimensionless Correlation Based on the Mass Transfer Model in Newly Developed Dialyzers and a Downsized Dialyzer
}

\author{
Makoto FuKUdA, , \# Koki NAMEKawa, ${ }^{* *}$ Kiyotaka SAKAI ${ }^{* * *}$
}

\begin{abstract}
The dialysis fluid flow and solute removal performance of newly developed dialyzers and a downsized dialyzer were evaluated using a dimensionless correlation equation related to the mass transfer coefficient of the dialysate-side film in a mass transfer model, which was used in quantitative analyses in our previous study. The solute removal performance is greatly dependent on the dialysis fluid flow for low molecular weight solutes. Hence, the recently developed dialyzers are based on new design concepts incorporating jackets or hollow fibers that provide an evenly distributed flow. The new dialyzers tested were APS-15SA, PES-15S $\alpha$ eco, PN-140S, and NV-15U. APS-15DSplus was used as a downsized version of the APS-15SA. The dialysate-side equivalent diameter $d_{\mathrm{e}}$ is smaller in the APS-15DSplus than in the APS-15SA, while the other design specifications are identical for these two devices. We measured vitamin $\mathrm{B}_{12}$ clearance with the dialyzers operated at a blood-side flow rate $Q_{\mathrm{B}}=$ $200 \mathrm{~mL} / \mathrm{min}$, dialysate-side flow rates $Q_{\mathrm{D}}=300-700 \mathrm{~mL} / \mathrm{min}$, and a net filtration rate $Q_{\mathrm{F}}=0 \mathrm{~mL} / \mathrm{min}$. We then calculated the overall mass transfer coefficient. Using this value, we derived the dimensionless correlation of the Sherwood number (Sh), which includes the dialysate-side film mass transfer coefficient $\left(k_{\mathrm{D}}\right)$ and Reynolds number $\left(R e_{\mathrm{D}}\right)$. The exponent of $R e_{\mathrm{D}}$ was approximately 0.5 for all the dialyzers. The newly developed dialyzers have various design features for improving dialysis fluid flow. Unlike previous devices, the various new designs result in a convergence of performance. A comparison of APS-15SA and the downsized APS-15DSplus showed similar dependence of $k_{\mathrm{D}}$ on $R e_{\mathrm{D}}$. This finding is novel and is attributed to the similarity in the relationship between dialysate-side fluid flow and dialysate-side film mass transfer in the two devices. In both dialyzers, the jacket has a full baffle and short taper structure, and the wave design of the hollow fiber membranes is identical. However, $d_{\mathrm{e}}$ was smaller in APS-15DSplus. Thus, analogous design concept employing the dimensionless correlation can be adopted for downsizing a device.
\end{abstract}

Keywords: dialyzer, dimensionless correlation, mass transfer model, mass transfer coefficient, Reynolds number.

Adv Biomed Eng. 5: pp. 118-123, 2016.

\section{Introduction}

The expectations from dialyzers have increased with recent developments in blood purification. Moreover, the number of home dialysis patients is increasing and there is a need to provide emergency medical treatment in times of disasters. Achieving both compact size and high performance has become a requirement for dialyzers, as is the case of other medical equipment [1]. However, downsizing a device may adversely affect its performance characteristics. Therefore, the relationship between dialysis fluid flow and the planned design concept should be verified as being analogous to that of a conventional dialyzer before the design concept can be adopted.

The solute removal performance is greatly dependent on the

Received on August 27, 2015; revised on May 18, 2016; accepted on June 8, 2016.

*Department of Biomedical Engineering, Kindai University, Wakayama, Japan.

** Department of Medical Engineering, Junshin Gakuen University, Fukuoka, Japan.

**** Professor Emeritus of Chemical Engineering, Waseda University, Tokyo, Japan.

\# 930 Nishimitani, Kinokawa, Wakayama 649-6433, Japan.

E-mail: fukuda@waka.kindai.ac.jp dialysis fluid flow [2]. Hence, the recently developed dialyzers are based on new design concepts incorporating jackets or hollow fibers that provide an evenly distributed flow [3-5]. We previously reported the results of quantitative analyses of the dialysis fluid flow and solute removal performance using mass transfer correlation equations [4]. The dimensionless correlation is related to the Sherwood number $\left(S h \equiv k_{\mathrm{D}} d_{\mathrm{e}} / D\right)$ and Reynolds number (Re $\equiv$ $\left.d_{\mathrm{e}} u \rho / \mu\right)$ including the mass transfer coefficient of the dialysate-side film $\left(k_{\mathrm{D}}\right)$ in a mass transfer model as well as the dialysate-side equivalent diameter $\left(d_{\mathrm{e}}\right)$, and has been used for evaluating the solute removal performance of a device from the viewpoint of design concept $[2,4]$. New design elements including a jacket with a full baffle and short taper structure, and a new wave design for the hollow fiber membranes have been introduced in new dialyzers to achieve a more even dialysis flow and better solute removal performance. The relationship between dialysis fluid flow and the above-mentioned new design concepts can be verified [4, 5].

In this study, we evaluated several newly developed dialyzers and a downsized dialyzer by quantitative analyses of the dialysis fluid flow and solute removal performance using the mass transfer correlation equations that we reported previously. The downsized dialyzer was modified from a newly designed dialyzer, in which the hollow fiber membrane was replaced by a thinner membrane, and the cross-sectional area $S_{\mathrm{D}}$ of the dialysate flow path and the dialysate-side equivalent diameter $d_{\mathrm{e}}$ were reduced. 
We derived the exponent of the $R e_{\mathrm{D}}$ number with respect to the $S h$ number, including the $k_{\mathrm{D}}$ in the mass transfer model and the $d_{\mathrm{e}}$. We also compared the downsized dialyzer and its conventional version using the dimensionless correlation based on the mass transfer model.

\section{Materials and Methods}

\subsection{Dialyzer}

The newly developed dialyzers used in our study were APS-15SA (Asahi Kasei Medical Co., Ltd., Tokyo, Japan) [3], PES-15S $\alpha e c o$ (Nipro Corporation, Osaka, Japan), PN-140S (Fresenius Medical Care Japan K.K., Tokyo, Japan/Nikkiso Co., Ltd., Tokyo, Japan), and NV-15U (Toray Industries, Inc.). Furthermore, the APS15DSplus (Asahi Kasei Medical Co., Ltd.) was used as a downsized version of the APS-15SA. The dialyzer specifications are presented in Table 1. The measured inner diameter of the jacket and effective length of the hollow fiber are shown. The membrane area $A$, cross-sectional area $S_{\mathrm{D}}$ of the dialysate flow path, dialysate flow velocity $u_{\mathrm{D}}$, and dialysate-side equivalent diameter $d_{\mathrm{e}}$ were calculated using Equations (1) to (4), respectively.

$$
\begin{aligned}
& A=\pi d L N \\
& S_{\mathrm{D}}=\frac{\pi\left\{d_{\mathrm{h}}^{2}-(d+2 \Delta)^{2} N\right\}}{4} \\
& u_{\mathrm{D}}=\frac{Q}{S_{\mathrm{D}}} \\
& d_{\mathrm{e}}=\frac{4 S_{\mathrm{D}}}{\pi\left\{d_{\mathrm{h}}+(d+2 \Delta) N\right\}}
\end{aligned}
$$

Here, $N$ is the number of hollow fibers; $Q$ is the dialysate flow rate; $d_{\mathrm{h}}$ is the inner diameter of the jacket; and $\Delta$ is the membrane thickness.

The design concept drawings of the jacket shape are shown in Fig. 1. The design elements include a full baffle and short taper structure for the APS-15SA and APS-15DSplus, and an interlocking pinnacle shape for the PN-140S. Moreover, all the devices are filled with wavy hollow fibers. Compared to APS-15SA, the APS-
15DSplus has a thinner membrane, a jacket with smaller inner diameter $d_{\mathrm{h}}$, and a smaller dialysate-side fluid path area. Hence, the dialysate-side equivalent diameter $d_{\mathrm{e}}$ is smaller in the APS15DSplus than in the APS-15SA, while all the other design specifications are identical for these two devices.

\subsection{Mass transfer correlation equation}

In mass transfer using a dialysis membrane, three resistances are connected in series: the blood-side film, dialysis membrane, and dialysate-side film. The overall mass transfer resistance is shown to be the sum of these resistances. When the mass transfer coefficients of the blood- and dialysate-side films are represented by $k_{\mathrm{B}}$ and $k_{\mathrm{D}}$, respectively, and the membrane diffusive permeability is represented by $k_{\mathrm{M}}$, the overall mass transfer coefficient $K_{\mathrm{L}}$ can be expressed as shown in Equation (5).

$$
\frac{1}{K_{\mathrm{L}}}=\frac{1}{k_{\mathrm{B}}}+\frac{1}{k_{\mathrm{M}}}+\frac{1}{k_{\mathrm{D}}}
$$

The mass transfer coefficients $k$ of the film are generally estimated using the mass transfer equation shown in Equation (6), which was obtained in analogy with the heat transfer equation for a laminar flow in a straight tube (parallel flow) reported by Colburn [6]. According to this equation, $k$ is proportional to the Reynolds number $\operatorname{Re}(\equiv d u \rho / \mu)$ raised to the power of $1 / 3$ [7].

$$
\begin{array}{r}
S h \equiv k d / D=1.62 \operatorname{Re}^{1 / 3} S c^{1 / 3}(d / L)^{1 / 3} \\
(\operatorname{Re} \cdot S c \cdot(d / L)>10)
\end{array}
$$

Here, Sh is the Sherwood number; $S c(\equiv \mu / \rho D)$ is the Schmidt number; $d$ is the inner diameter of the hollow fiber; $u$ is the flow velocity; $\rho$ is the solution density; $\mu$ is the solution viscosity; $D$ is the solute diffusion coefficient; and $L$ is the effective length of the

\begin{tabular}{|c|c|c|c|c|c|c|}
\hline dialyzer & & APS-15SA & APS-15DSplus & PES-15S $\alpha e c o$ & PN-140S & $\mathrm{NV}-15 \mathrm{U}$ \\
\hline manufacturer & & Asahi Kasei & Asahi Kasei & Nipro & $\begin{array}{l}\text { Fresenius } \\
\text { Medical Care } \\
\text { Japan/Nikkiso }\end{array}$ & Toray \\
\hline material & & polysulfone & polysulfone & polyethersulfone & polysulfone & polysulfone \\
\hline membrane surface area & {$\left[\mathrm{m}^{2}\right]$} & 1.5 & 1.5 & 1.5 & 1.4 & 1.5 \\
\hline inner diameter of hollow fiber & {$[\mu \mathrm{m}]$} & 185 & 185 & 200 & 185 & 200 \\
\hline effective length of hollow fiber & {$[\mathrm{cm}]$} & 26.5 & 26.5 & 27.0 & 25.4 & 27.0 \\
\hline membrane thickness & {$[\mu \mathrm{m}]$} & 45 & 35 & 40 & 35 & 40 \\
\hline filtration coefficient ${ }^{1)}$ & {$[\mathrm{ml} / \mathrm{hr} / \mathrm{mmHg}]$} & 63 & 51 & 44 & 22 & 45 \\
\hline fiber density & {$[\%]$} & 58 & 58 & 60 & 62 & 59 \\
\hline inner diameter of dialyzer & {$[\mathrm{cm}]$} & 3.6 & 3.3 & 3.6 & 3.2 & 3.5 \\
\hline dialysate flow area & {$\left[\mathrm{cm}^{2}\right]$} & 4.5 & 3.7 & 4.7 & 3.2 & 4.0 \\
\hline dialysate equivalent diameter & {$[\mu \mathrm{m}]$} & 215 & 189 & 240 & 159 & 199 \\
\hline shape of hollow fiber & & wavy & wavy & wavy & wavy & wavy \\
\hline jacket design & & $\begin{array}{l}\text { full baffle } \\
\text { short taper }\end{array}$ & $\begin{array}{l}\text { full baffle } \\
\text { short taper }\end{array}$ & partial baffle & pinnacle structure & partial baffle \\
\hline
\end{tabular}
hollow fiber.

In this analysis, $S h$ on the left-hand side of the equation represents the mass transfer rate, including the film mass transfer coefficient $\left(k_{\mathrm{D}}\right)$ of the dialysate-side fluid; Re on the right-hand side of the equation is the Reynolds number of the dialysis fluid;

Table 1 Technical data of the dialyzers tested.

${ }^{1)}$ Total protein was $6.0 \pm 0.5 \mathrm{~g} / \mathrm{dl}$ and transmembrane pressure (TMP) was $50 \mathrm{mmHg}$, in plasma. 


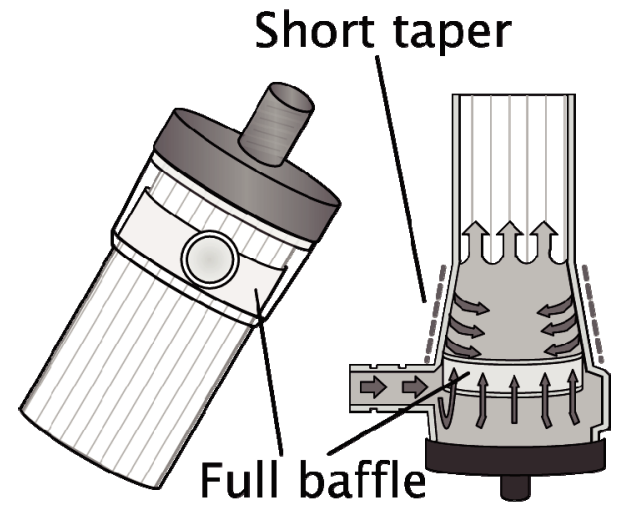

(a)

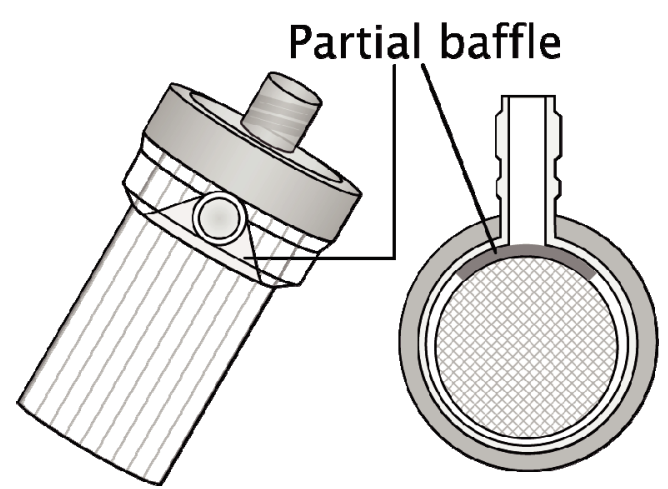

(b)

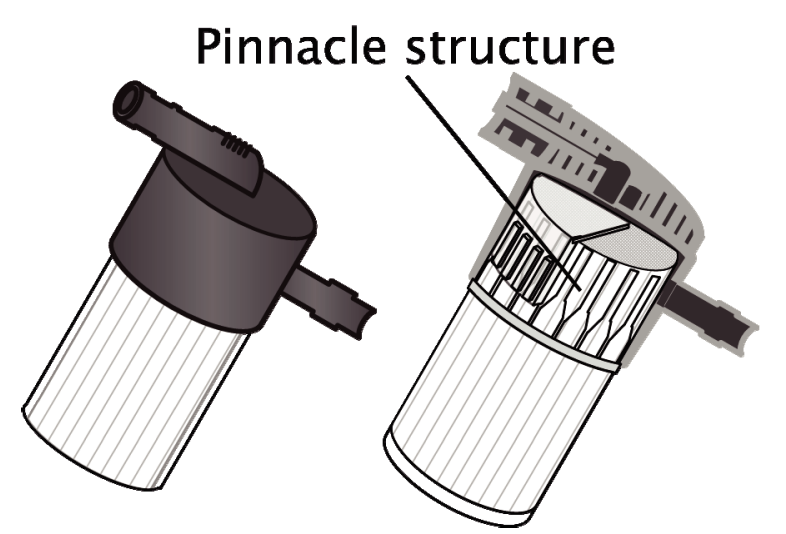

(c)

Fig. 1 Schematic diagrams of dialyzer jackets. (a) APS-15SA and APS-15DSplus, (b) PES-15S $\alpha$ eco and NV-15U, and (c) PN$140 S$.

and $S c$ is the Schmidt number including the solute diffusivity. In other words, a quantitative assessment may be possible by connecting dialysate-side fluid flow and mass transfer by a dialyzer design concept.

In previous dialyzers, in which the dialysate-side flows were uneven, $k_{\mathrm{D}}$ was reported to be proportional to $R e$ raised to the power of 1.0 [2], as shown in Equation (7).

$$
\begin{gathered}
S h \equiv k_{\mathrm{D}} d_{\mathrm{e}} / D=1.80 R e^{1.0} S c^{1 / 3}\left(d_{\mathrm{e}} / L\right)^{1 / 2} \\
(1<\operatorname{Re}<20)
\end{gathered}
$$

Here, $d_{\mathrm{e}}$ is the dialysate-side equivalent diameter, and $R e$ is de- fined by $d_{\mathrm{e}}$.

For the film mass transfer coefficient of the region outside the capillaries in a flow that runs orthogonal to the capillary layer, the dimensionless correlation is obtained as shown in Equation (8) $[8,9]$.

$$
\begin{aligned}
S h \equiv k d / D= & 0.80 R e^{0.47} S c^{0.33} \\
& (0.1<\operatorname{Re}<10)
\end{aligned}
$$

Moreover, for the abovementioned dialyzers, the dimensionless correlation can be obtained with Equation (9) [4].

$$
\begin{gathered}
S h \equiv k_{\mathrm{D}} d_{\mathrm{e}} / D \propto R e^{0.47-0.56} \\
(2<\operatorname{Re}<9)
\end{gathered}
$$

Equations (6)-(9) indicate that the relationship between $k$ and $R e$ depends on the physical situation of the fluid-solid interfaces. In particular, the dialysis fluid flow is more complicated in this geometry because of the close packing of the fibers. $k_{\mathrm{D}}$ is usually obtained from the overall mass transfer coefficient, which is calculated from the measured solute clearance using Equation (10). This equation assumes no loss in the membrane surface area, and a uniform dialysis fluid flow velocity and solute concentration across the dialyzer cross-section. Therefore, the fiber-fiber contact, nonuniform dialysis fluid flow, and dialysis fluid channeling lead to a decrease in the apparent $k_{\mathrm{D}}$. These phenomena, which are expected on the dialysis fluid-side, can impact both the magnitude of $k_{\mathrm{D}}$ and its dependence on the exponent $x$ of $R e_{\mathrm{D}}$ $\left(R e_{\mathrm{D}}{ }^{x}\right)$

\subsection{Dialysis experiment}

To derive the mass transfer coefficient of the dialysate-side film $k_{\mathrm{D}}$ and exponent of the $R e$ number, we measured vitamin $\mathrm{B}_{12}$ (6 mg\%, MW 1355) clearances at different dialysate-side flow rates. For a blood-side flow rate $Q_{\mathrm{B}}$ of $200 \mathrm{~mL} / \mathrm{min}$ and a net filtration rate $Q_{\mathrm{F}}$ of $0 \mathrm{~mL} / \mathrm{min}$, the dialysate-side flow rates $Q_{\mathrm{D}}$ of $300,400,500,600$, and $700 \mathrm{~mL} / \mathrm{min}$ were tested. The vitamin $\mathrm{B}_{12}$ concentration was calculated from the absorbance at the peak wavelength of $390 \mathrm{~nm}$. The overall mass transfer coefficient $K_{\mathrm{L}}$ was calculated from Equation (10).

$$
K_{\mathrm{L}}=\frac{Q_{\mathrm{B}}}{A\left(1-Q_{\mathrm{B}} / Q_{\mathrm{D}}\right)} \ln \left(\frac{1-C_{\mathrm{L}} / Q_{\mathrm{D}}}{1-C_{\mathrm{L}} / Q_{\mathrm{B}}}\right)
$$

Here, $C_{\mathrm{L}}$ is the clearance, and $A$ is the membrane area. The mass balance error, \%MBE, was calculated using Equation (11), and the value of $\% \mathrm{MBE}$ was less than $10 \%$ [10].

$$
\% M B E=\frac{\left(Q_{\mathrm{BI}} C_{\mathrm{BI}}-Q_{\mathrm{BO}} C_{\mathrm{BO}}\right)-Q_{\mathrm{D}} \times C_{\mathrm{DO}}}{Q_{\mathrm{BI}} C_{\mathrm{BI}}-Q_{\mathrm{BO}} C_{\mathrm{BO}}} \times 100
$$

Here, BI stands for the inlet at the blood side; во the outlet at the blood side; and DO the outlet at the dialysate side.

\subsection{Deriving mass transfer coefficient of dialysate-side and Reynolds number exponent using Wilson plot}

The film mass transfer coefficient $k$ and flow speed $u$ are related as shown in Equation (12).

$$
k \propto u^{x}
$$

Therefore, when a dialysis experiment is conducted for a constant blood-side flow rate $Q_{\mathrm{B}}$ and varying dialysate-side flow rates $Q_{\mathrm{D}}$, Equation (5) can be rewritten as shown in Equation (13).

$$
\frac{1}{K_{\mathrm{L}}}=\frac{1}{k_{\mathrm{B}}}+\frac{1}{k_{\mathrm{M}}}+\frac{1}{a R e_{\mathrm{D}}^{x}}
$$

Here, $a$ is a constant, and $R e_{\mathrm{D}}$ is the dialysate-side Reynolds num- 
ber.

The measured values for $K_{\mathrm{L}}$ were plotted on a graph, with 1/ $K_{\mathrm{L}}$ on the vertical axis and the inverse of $R e_{\mathrm{D}}$ raised to the $x$ pow$\operatorname{er}\left(1 / R e_{\mathrm{D}}{ }^{x}\right)$ on the horizontal axis. This graph is the so-called Wilson plot. The exponent $x$ for $R e_{\mathrm{D}}$ was set such that the correlation coefficient became closer to one, thus aligning the plot with a straight regression line. Owing to the choice of the exponent, the extrapolated point of the line at $R e_{\mathrm{D}} \rightarrow \infty$, i.e., the intercept at the vertical axis, $1 / k_{\mathrm{B}}+1 / k_{\mathrm{M}}$. Moreover, from the Wilson plot obtained, the mass transfer coefficient of the dialysate-side film $k_{\mathrm{D}} \mathrm{S}$

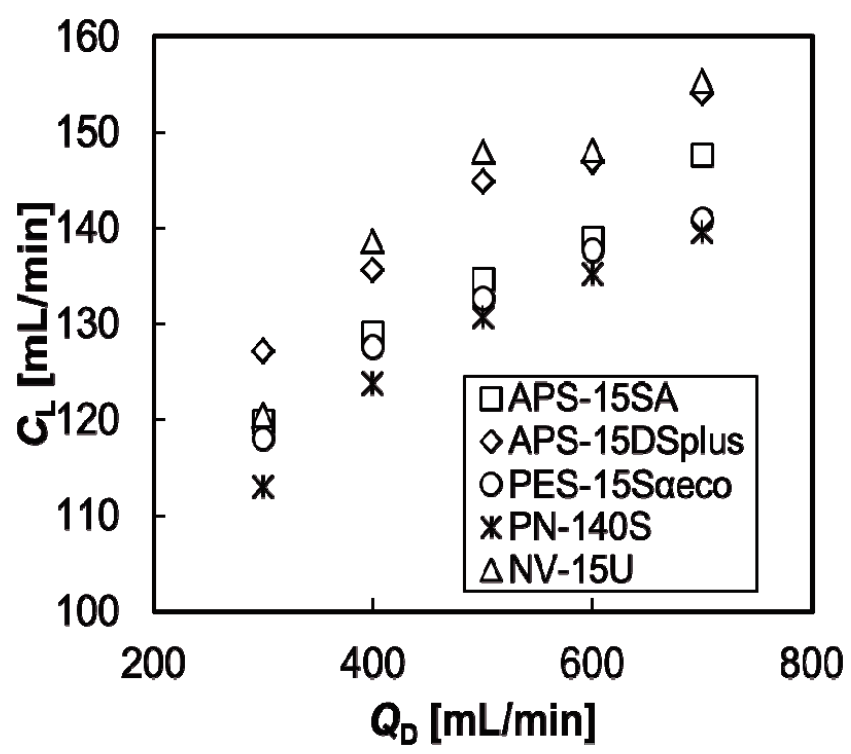

(a)

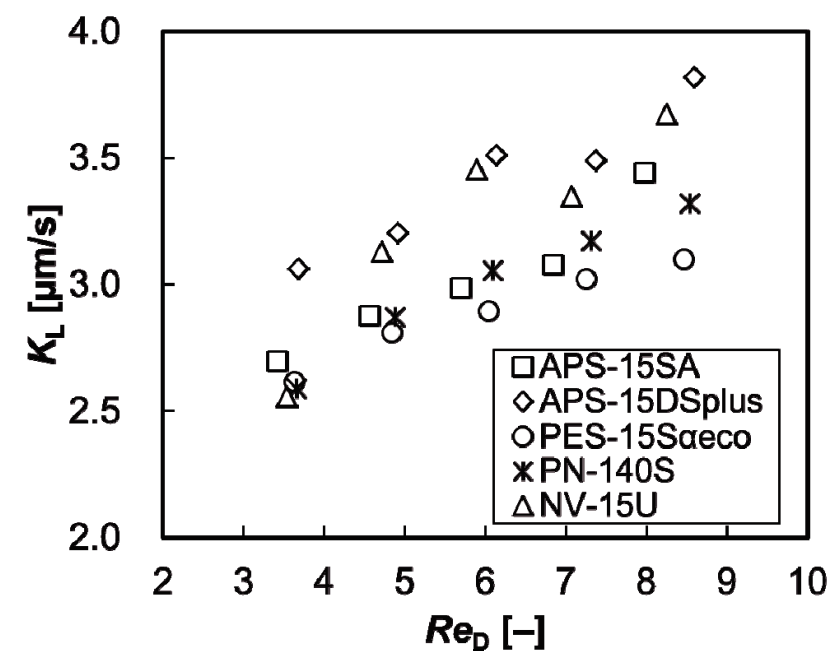

(b)

Fig. 2 Vitamin $\mathrm{B}_{12}$ clearance and overall mass transfer coefficient $\left(Q_{\mathrm{B}}=200 \mathrm{~mL} / \mathrm{min}, Q_{\mathrm{D}}=300-700 \mathrm{~mL} / \mathrm{min}, Q_{\mathrm{F}}=0 \mathrm{~mL} / \mathrm{min}\right)$. (a) Clearance $C_{\mathrm{L}}$ at various dialysate flow rates. (b) Overall mass transfer coefficient $K_{\mathrm{L}}$ against dialysate Reynolds number. $C_{\mathrm{L}}$ and $K_{\mathrm{L}}$ are greater in APS-15DSplus $(\diamond)$ than in APS15SA ( $\square)$. This results from an increase in membrane diffusive permeability $k_{\mathrm{M}}$ attributed to the thinner membrane. Thus, the intercept $\left(1 / k_{\mathrm{B}}+1 / k_{\mathrm{M}}\right)$ in Fig. 3(b) is smaller for APS15DSplus. for each flow rate $\left(R e_{\mathrm{D}}\right)$ was derived using Equation (5).

\section{Results}

Figure 2 shows the measured clearance $C_{\mathrm{L}}$ and overall mass transfer coefficient $K_{\mathrm{L}}$. The devices in decreasing order of $C_{\mathrm{L}}$ were NV-15U, APS-15DSplus, APS-15SA, PES-15S $\alpha$ eco, and PN-140S. The APS-15DSplus and NV-15U had the largest $K_{\mathrm{L}}$. The other three dialyzers had similar $K_{\mathrm{L}}$, indicating that their mass transfer rates per unit membrane area were similar.

The Wilson plot is shown in Fig. 3. The derived Reynolds number exponent and the correlation coefficients between $1 / K_{\mathrm{L}}$ and $1 / \operatorname{Re}_{\mathrm{D}}{ }^{\mathrm{X}}$ for each dialyzer are listed in Table 2 . The correlation coefficients for the regression lines on the Wilson plot were $0.95,0.96,0.99,0.99$, and 0.94 for the five dialyzers.

The dialysate-side film mass transfer coefficient $k_{\mathrm{D}}$ is shown in Fig. 4. The devices in decreasing order of $k_{\mathrm{D}}$ were PES-15S $\alpha e$ co, APS-15DSplus, APS-15SA, PN-140S, and NV-15U.

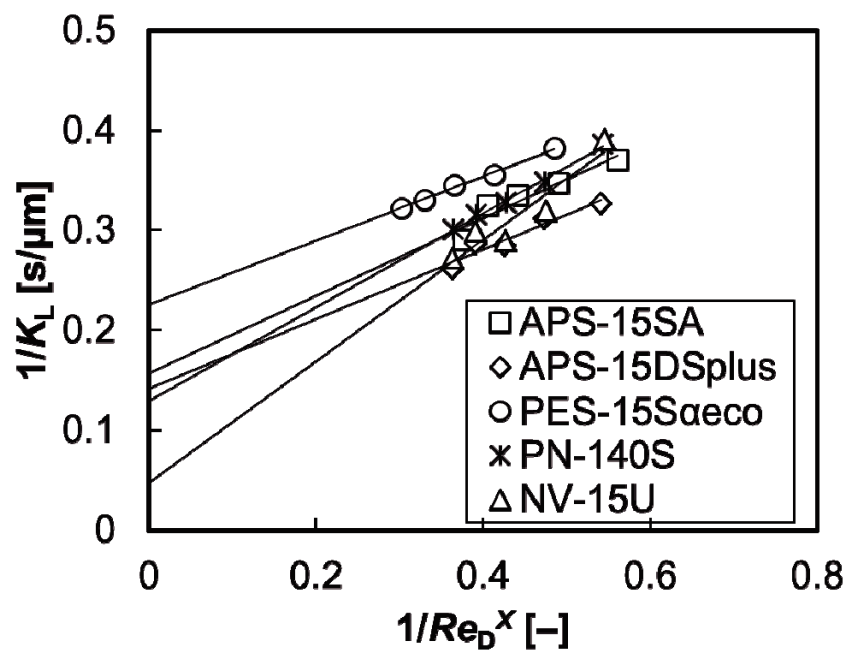

(a)

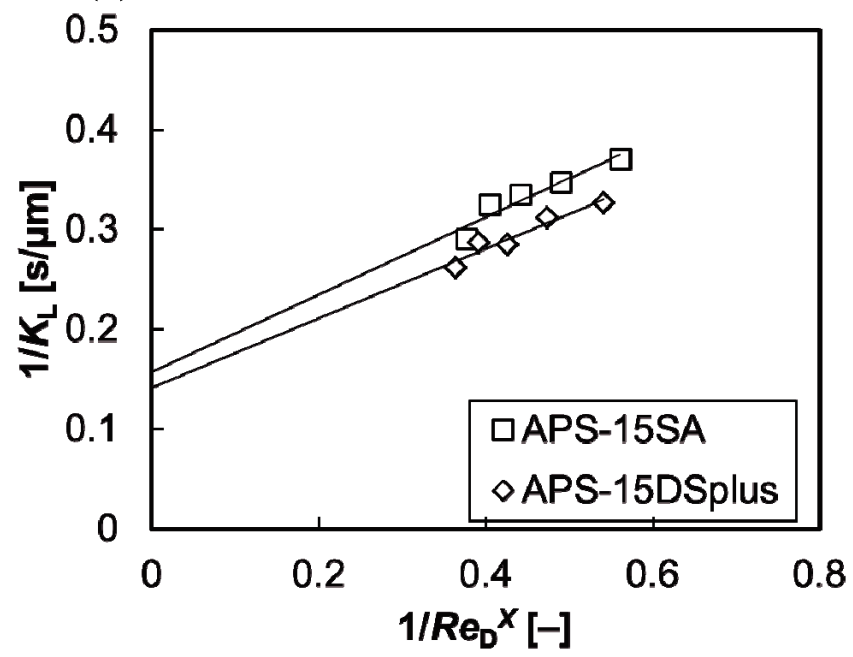

(b)

Fig. 3 Wilson plots of $1 / K_{\mathrm{L}}$ against $1 / \operatorname{Re}_{\mathrm{D}}{ }^{\mathrm{X}}$ for vitamin $\mathrm{B}_{12}$ : (a) for all dialyzers and (b) for APS-15SA and APS-15DSplus only. 
Table 2 Exponent of $R e$ and correlation coefficient between $1 / K_{\mathrm{L}}$ and $1 / \operatorname{Re}_{\mathrm{D}} \mathrm{x}$.

\begin{tabular}{lcc}
\hline \hline dialyzer & exponent [-] & correlation coefficient [-] \\
\hline APS-15SA & 0.47 & 0.95 \\
APS-15DSplus & 0.47 & 0.96 \\
PES-15S $\alpha$ eco & 0.56 & 0.99 \\
PN-140S & 0.47 & 0.99 \\
NV-15U & 0.48 & 0.94 \\
\hline \hline
\end{tabular}

\section{Discussion}

4.1 Downsized dialyzer and dialysis mass transfer coefficients

Larger $k_{\mathrm{D}}$ is associated with better dialysis fluid flow. All the dialyzers had wavy hollow fiber membranes. The APS-15DSplus and APS-15SA had a full baffle and short taper jacket structure, facilitating uniform dialysis fluid flow. Another factor contributing to the uniform dialysis flow was the greater ease of flow of the dialysate in the central portion of the hollow fiber bundle, i.e., improved uniformity of the dialysate flow and enhanced mass transfer.

A comparison of the APS-15SA with the downsized device APS-15DSplus showed that the dependence of $k_{\mathrm{D}}$ on the Reynolds number was similar in both devices (Fig. 4). This is a novel finding. This similarity in dependence of $k_{\mathrm{D}}$ on the Reynolds number was attributed to the similarity in the relationship between the dialysate-side fluid flow and the dialysate-side film mass transfer in the two devices. Furthermore, both had identical exponent, and the relationship between Reynolds number for the dialysate-side fluid flow and dialysate-side film mass transfer coefficient was similar for APS-15SA and the downsized device APS-15DSplus. $C_{\mathrm{L}}$ and $K_{\mathrm{L}}$ were also higher in the APS-15DSplus than in the APS-15SA, as shown in Fig. 2. This was due to an increase in membrane diffusive permeability $k_{\mathrm{M}}$, which was attributed to the thinner membrane. Thus, the intercept in Fig. $\mathbf{3}$ is lower for the APS-15DSplus.

4.2 Dialysate mass transfer coefficient and exponent of Reynolds number in dimensionless correlation equation As described in Materials and Methods, the exponent of the Reynolds number is determined by the dialysate-side flow in a dialyzer. From our results, the exponent of the Reynolds number was approximately 0.5 for all the dialyzers, whereas the theoretical exponent of the Reynolds number was $1 / 3$ for a laminar flow in a cylindrical pipe (parallel flow). The reason for this discrepancy is that the complex, non-parallel flow inside the dialyzer promotes the mass transfer, even though the Reynolds number range for the experimental flow rate is within $2<R e_{\mathrm{D}}<10$ and the flow is thought to be laminar. For $R e<20$, the flow is orthogonal in the evenly spaced hollow fiber membranes, and the exponent of the Reynolds number was reported to be 0.47 [4]. The exponent obtained in this study implies that in the dialyzers we investigated, the orthogonal flow contributes more significantly to the mass transfer rate than does the parallel flow, and the development of such a complex fluid flow leads to the improvement in the mass transfer.

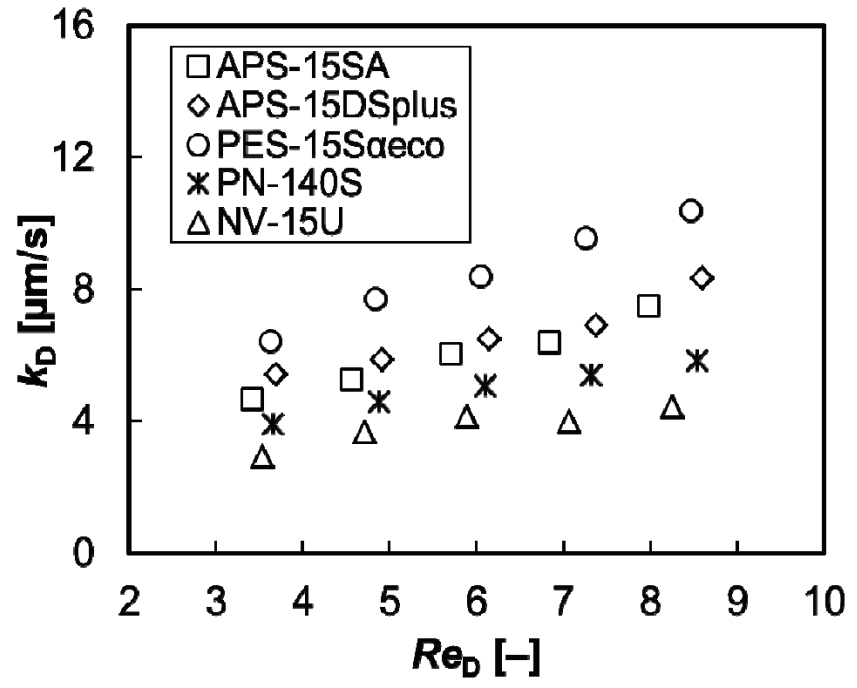

(a)

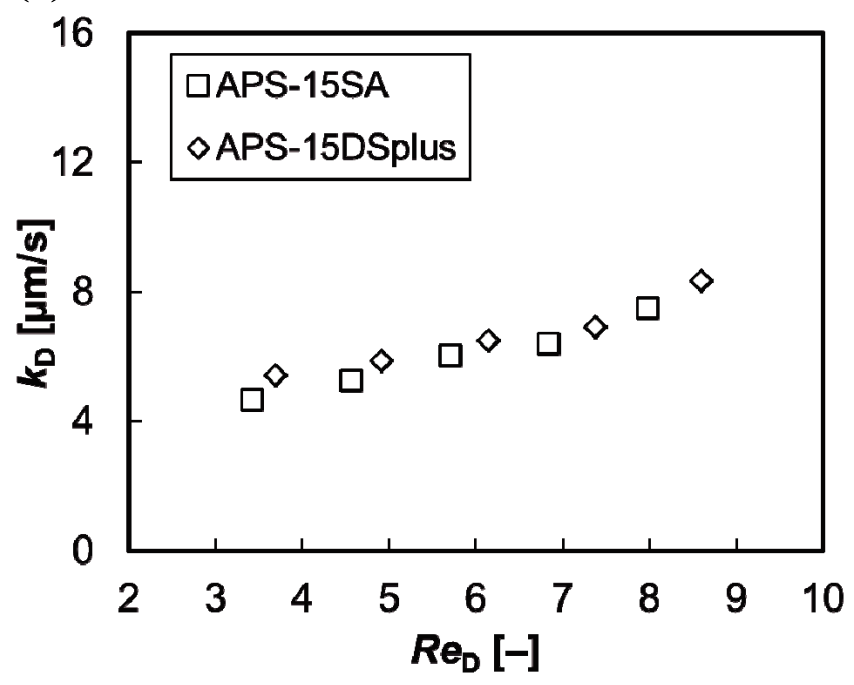

(b)

Fig. 4 Dialysate-side film mass transfer coefficient $k_{\mathrm{D}}$ against dialysate Reynolds number $\operatorname{Re}_{\mathrm{D}}$ : (a) for all dialyzers and (b) for APS-15SA and APS-15DSplus only. The dialyzers have jackets with full baffle and short taper structure and the same wavy hollow fiber membranes.

\subsection{Dialysate-side film mass transfer coefficient $k_{\mathrm{D}}$, includ-} ing effects of internal filtration.

The dialyzers used in this research were super-high flux dialyzers with high filtration coefficients, in which mass transfer is achieved by diffusion and filtration (convection). The mechanism of the film formation in the vicinity of a membrane during membrane permeation is extremely complex [11]. Even when the net filtration rate $Q_{\mathrm{F}}$ is set to $0 \mathrm{ml} / \mathrm{min}$, the transfer of vitamin $\mathrm{B}_{12}$ may be promoted because of the increased internal filtration rate associated with the increase in dialysate flow rate $Q_{\mathrm{D}}$. Therefore, the value of the dialysate-side film mass transfer coefficient $k_{\mathrm{D}}$ obtained in this study is an "apparent" number that accurately includes the effects of the internal filtration in the dialyzer.

On the other hand, we adopted the so-called Wilson plot method in this study because the transfer of vitamin $\mathrm{B}_{12}$ is considered to be primarily due to diffusion. The Wilson plot assumes a 
laminar film model, and the effects of the internal filtration on the dialysate-side film and mass transfer coefficient in a dialyzer cannot be analyzed very accurately. Hardly any transfer occurs as a result of filtration, because substances ranging from urea (MW 60 ) and creatinine (MW 113) to the molecular weight equivalent of $\beta_{2}$-microglobulin (MW 11800) have higher diffusion coefficients $[12,13]$. Thus, the transfer of vitamin $\mathrm{B}_{12}$ (MW 1355) is also considered to be primarily due to diffusion. Even in the presence of myoglobin (MW 17000), which has a larger molecular weight than vitamin $\mathrm{B}_{12}$, transfer due to filtration is estimated to constitute about $5 \%$ of the total transfer, for a dialyzer equivalent to the APS-15SA at $Q_{\mathrm{F}}=0 \mathrm{ml} / \mathrm{min}$ [14].

A comparison of the APS-15SA and the downsized APS15DSplus showed similar dependence of $k_{\mathrm{D}}$ on the Reynolds number in both dialyzers. It was because the effects of the internal filtration on the dialysate-side film and mass transfer coefficient in a dialyzer must be analyzed very accurately, it must be emphasized that this was also because the relationship between the dialysate-side fluid flow and the internal filtration in the dialyzers was analogous.

The devices in decreasing order of $k_{\mathrm{D}}$ are PES-15S $\alpha$ eco, APS-15DSplus, APS-15SA, PN-140S, and NV-15U in Fig. 4(a). This order may be explained by the complex effects of jacket shape, wavy hollow fiber membrane design, and filtration coefficient of the dialyzers.

\section{Conclusion}

Using the mass transfer model, we established the analogy between a newly developed dialyzer and its downsized version in terms of the dimensionless relationship between Reynolds number of the dialysate flow and dialysate-side mass transfer coefficient from the viewpoint of the design concept. Thus, analogous design concept employing the dimensionless correlation can be adopted for downsizing a device.

\section{Conflict of interest}

The authors have no conflict of interest.

\section{References}

1. Kokubo K, Kurihara Y, Kobayashi K, Moriguchi T, Matsuda K, Kobayashi H: Development of the hemofilter using the thinner hollow fiber. Jpn J Artif Organs. 43(3), pp. 238-241, 2014.

2. Fukuda M, Hosoya N, Kanamori T, Sakai K, Nishikido J, Watanabe $\mathrm{T}$, et al.: Determination of optimal fiber density of convection and high performance dialyzers. Artif Organs Today. 2, pp. 205-214, 1992.

3. Fukuda M, Miyazaki M, Uezumi S, Yoshida M: Design and assessment of the new APS dialyzer (APS-SA series). J Artif Organs. 9, pp. 192-198, 2006.

4. Kunikata S, Fukuda M, Yamamoto K, Yagi Y, Matsuda M, Sakai $\mathrm{K}$ : Technical characterization of dialysis fluid flow of newly-developed dialyzers using mass transfer correlation equations. ASAIO J. 55, pp. 231-235, 2009.

5. Yamamoto K, Matsuda M, Hirano A, Takizawa N, Iwashima S, Yakushiji T, Fukuda M, Miyasaka T, Sakai K: Computational evaluation of dialysis fluid flow in dialyzers with variously designed jackets. Artif Organs. 33(6), pp. 481-486, 2009.

6. Colburn AP: A method of correlating forced convection heat transfer data and a comparison with fluid friction. Trans Am Inst Chem Engs. 29, pp. 174-210, 1933.
7. Cussler EL. Diffusion: Mass Transfer in Fluid Systems. 2nd ed. New York: Cambridge University Press; 1997.

8. Wickramasinghe SR, Semmens MJ, Cussler EL: Hollow fiber modules made with hollow fiber fabric. J Membr Sci. 84, pp. 1-14, 1993.

9. Wickramasinghe SR, Semmens MJ, Cussler EL: Mass transfer in various hollow fiber geometries. J Membr Sci. 69, pp. 235-250, 1992.

10. Kawanishi H, Mineshima M, Hirakata H, Akizawa T: Measurement of clearances of hemodialyzer and hemodiafilter. Tousekikaishi. 45(5), pp. 435-445, 2012 (in Japanese).

11. Kanamori T, Mizoguchi K. Solute-removal enhancement caused by local convective flow in a hemodialyzer. J Artif Organs. 15, pp. 305-310, 2012.

12. Tomo T, Matsuyama M, Nakata T, Kadota J, Toma S, Koga N, Fukui H, Arizono K, Takamiya T, Matsuyama K, Ueyama S, Shiohira Y, Uezu Y, Higa A: Effect of high fiber density ratio polysulfone dialyzer on protein removal. Blood Purif. 26(4), pp. 347-353, 2008.

13. Mineshima M, Ishimori I, Sekiyama R. Validity of internal filtration-enhanced hemodialysis as a new hemodiafiltration therapy. Blood Purif. 27, pp. 33-37, 2009.

14. Sekino M. Effect of ultrafiltration in hemodiafiltration system. Kagakukougaku ronbunsyu. 38(3), pp. 155-160, 2012 (in Japanese).

\section{Fukuda Макото}

Academic Carrier: Department of Chemical Engineering, Waseda University (1993), Ph.D (Engineering), Department of Chemical Engineering, Waseda University (1999). Professional Carrier: Asahi Kasei Industry (1993-2005), Assistant Professor, Department of Medical Engineering, Himeji Dokkyo University (2006-2013), Assistant Professor, Department of Medical Engineering, Kindai University (2014-). Research fields: Artificial kidney, biomedical engineering.

\section{Namekawa KокI}

Academic Carrier: Ph.D (Engineering), Department of Chemical Engineering, Waseda University (2012). Professional Carrier: Postdoctoral Researcher, National Institute of Material Sciences (NIMS) (20122015), Assistant Professor, Department of Medical Engineering, Junshin Gakuen University (2015-). Research fields: Biomaterials, biomedical engineering. 